\title{
David Oliver: Why shouldn't hospitals challenge inspections?
}

\author{
David Oliver consultant in geriatrics and acute general medicine, Berkshire
}

England's health regulator, the Care Quality Commission (CQC), recently judged Addenbrooke's Hospital in Cambridge as "inadequate" and instigated special measures. ${ }^{1}$ The hospital's reputation guaranteed headlines, ${ }^{2}$ as did the resigning chief executive's self defence. ${ }^{3}$ Commentators fanned the flames, questioning the value of over-zealous regulation. ${ }^{4}$

The CQC then published a blog, Shooting the Messenger, which said that inspected hospitals shouldn't waste time contesting findings but rather should apologise and deliver the changes needed. ${ }^{5}$

I can't dispute the specifics of the Addenbrooke's judgment. But I will defend hospitals' right to challenge or explain. Inspections have statutory force. They can trigger resignations, worsen staff morale and recruitment, and damage public confidence. Does this help patients?

There's no inconsistency between a hospital taking immediate action on serious care failings and yet speaking out on an inspection's quality and fairness or explaining mitigating factors (not "excuses") in its wider ecosystem.

Under newish leadership the CQC has transformed and expanded its approach to inspections. But its journey to infallibility has been tortuous. In leaked minutes its inspectors described an intolerable workload, poor support, and inconsistency. ${ }^{6}$ The CQC has advertised for specialist advisers, acknowledging its lack of clinicians for expert peer inspection of services. To frontline staff, credibility and track record count. ${ }^{7}$ This includes the track record of inspectors in their own organisations and careers.

In the CQC's own quarterly performance report it rated itself as "requires improvement" across most domains. ${ }^{8}$ It also highlighted internal disciplinary actions for plagiarism, poor behaviour by inspectors, and breaches of protocol. Similar behaviours were reported in the Health Service Journal. ${ }^{9}$ An independent review of the hospital inspection process commissioned by the CQC described a steadily improving but still inconsistent process with ratings too dependent on professional judgment. ${ }^{10}$

The CQC has used its own growing workload, reorganisation, funding, and staffing to explain its variable performance and delays to hospital reports. ${ }^{11}{ }^{12}$ But it doesn't extend such mitigation to the hospitals it inspects.

Addenbrooke's is but one example of an English hospital struggling to recruit and retain nurses and to staff wards safely, partly because of local living costs and a failure to train enough UK nurses or to make permanent posts attractive. Like most English hospitals, it faces growing urgent demand, funding pressures, and "exit block," with a lack of capacity and reduced funding in local community and social care. Hospitals have some responsibility in tackling these system issues. But they're not islands. I'd say they have a positive duty to air them for the good of the whole NHS.

Shooting the messenger would be hypocritical, so I don't expect the CQC to reply to this. Better for it to tackle its problems compliantly rather than waste time justifying them.

Competing interests: I have read and understood BMJ policy on declaration of interests and have no relevant interests to declare.

Provenance and peer review: Commissioned; not externally peer reviewed.

thebmj.com Feature: What went wrong at Addenbrooke's? (BMJ 2015;351:h5278, doi:10.1136/bmj.h5278)

1 Care Quality Commission. Inspection report: Cambridge University Hospitals NHS Foundation Trust. 22 Sep 2015. www.cqc.org.uk/sites/default/files/new_reports/AAAD0110. pdf.

2 Campbell D, Elgot J. Addenbrooke's hospital in special measures after serious staff shortages. Guardian 2015 Sep 22. www.theguardian.com/society/2015/sep/22/prestigiousnhs-hospital-in-special-measures-after-serious-staff-shortages.

3 Addenbrooke's Hospital ex-chief says CQC assessment wrong. BBC News 2015 Sep 18 www.bbc.co.uk/news/uk-england-cambridgeshire-34292835.

4 West D. The NHS can't afford to put everyone in turnaround. Health Serv J 2015 Sep 25 www.hsj.co.uk/comment/leader/the-nhs-cant-afford-to-put-everyone-in-turnaround/5090634. article.

5 Sutcliffe A. Shooting the messenger. CQC Blogs 2015 Sep 25. www.cqc.org.uk/content/ shooting-messenger.

6 Cooper C. Hospital inspectors facing "intolerable" workload, leaked CQC documents reveal. Independent 2014. http://bit.ly/1LdolWb.

7 Care Quality Commission. Join an inspection as a specialist advisor. 23 Sep 2015. www. cqc.org.uk/content/join-inspection-specialist-advisor.

8 Care Quality Commission. Quarterly performance and finance report: Q4 end of year 2014-15. 21 May 2015. www.cqc.org.uk/sites/default/files/CM051505_Item_5_Q4_ performance_appen_1.pdf.

9 McLellan A. The CQC hospital inspection process "requires improvement." Health Serv J2014 Oct 14. www.hsj.co.uk/comment/leader/the-cqc-hospital-inspection-regime-requiresimprovement/5075768.article.

10 Manchester Business School, King's Fund. Evaluating the Care Quality Commission's acute hospital regulatory model: final report. Jul 2014. www.cqc.org.uk/sites/default/files/ 
CM071406\%20Item\%206\%20Acute\%20regulatory\%20model\%20evaluation\%20report. pdf.

11 Brindle D. David Behan: a reluctant rescuer of the crisis hit care regulator. Guardian 2014 Apr 9. www.theguardian.com/society/2014/apr/09/david-behan-rescue-care-regulatorcrisis.
12 Hazell W. CQC's board concerned over hospital report delays. Health Serv J 2015 Apr 24. www.hsj.co.uk/news/cqcs-board-concerned-over-hospital-report-delays/5084479. article.

Cite this as: BMJ 2015;351:h5320

(c) BMJ Publishing Group Ltd 2015 